\title{
Socioeconomic deprivation, ethnicity, and stroke mortality in Greater London and south east England
}

\author{
Ravi Maheswaran, Paul Elliott, David P Strachan
}

\begin{abstract}
Objective and setting - To examine geographical variation in stroke mortality in Greater London compared with the surrounding South East Region of England.

Design - Cross sectional, ecological analysis based on electoral wards.

Subjects - Resident population aged 45 years or more.

Main outcome measure - Age specific stroke mortality rates in five age bands, 1986-92.

Main results - In the 45-54 years age band, stroke mortality rate ratios $(95 \%$ confidence intervals) relative to the surrounding south east were $2.09(1.81,2.4)$ for Inner London and $1.31(1.15,1.5)$ for Outer London for men and $1.64(1.4,1.93)$ and $1.13(0.98,1.31)$ respectively for women. This gradient diminished and reversed with increasing age. In the $85+$ age band, rate ratios were $0.82(0.76,0.89)$ for Inner London and $0.89(0.84,0.94)$ for Outer London for men and $0.8(0.75,0.85)$ and $0.88(0.84,0.92)$ respectively for women. Carstairs deprivation index and the percentages of Afro-Caribbean men and women and Irish born men were significantly and positively correlated with stroke mortality at the ward level. The Carstairs effect diminished with increasing age. Adjustment for these variables diminished or abolished the higher stroke mortality risks in London for younger people but had little effect on the lower risks for older Londoners.

Conclusions - Higher rates of stroke mortality among middle aged adults in Greater London, compared with the surrounding South East Region, are associated with socioeconomic deprivation and ethnicity. These factors do not explain the relatively lower stroke mortality among older Londoners.
\end{abstract}

\section{(f Epidemiol Community Health 1997;51:127-131)}

Department of Public Health Sciences, St George's Hospital Medical School, London

D Strachan

Correspondence to: Dr R Maheswaran, Department of Epidemiology and Public Health, Imperial College School of Medicine London W2 1PG.

Accepted for publication June 1996
Within Greater London there is variation in stroke mortality rates across district health authorities, with high rates in Inner London for people under 65 years of age. ${ }^{2}$ Socioeconomic deprivation is associated with raised mortality from stroke. ${ }^{34}$ Stroke mortality also varies by ethnic group. ${ }^{56}$ In a national study of migrants to England and Wales, relative risks of mortality from stroke were raised for men and women born in the Caribbean and African Commonwealth, Indian subcontinent, and Ireland. ${ }^{5}$ As parts of London, particularly Inner London, have high levels of deprivation and relatively high populations of people from ethnic minority groups, these factors could explain the variation in stroke mortality.

The aim of this study therefore was to examine geographical variation in stroke mortality in Greater London compared with the surrounding South East Region in relation to socioeconomic deprivation and ethnicity.

\section{Methods}

The electoral ward was used as the unit of analysis. In 1991, there were 300 in Inner London, 460 in Outer London, and 2176 in the surrounding South East Region. A further 160 wards with no resident population were excluded from the analysis.

Deaths from 1986-92 were combined as numbers at the ward level in 10 year age bands were very small. Stroke deaths were defined as those classified under International Classification of Disease (9th revision) codes 430-438. These data were obtained in five age bands: $45-54$, $55-64,65-74,75-84$ and 85 or more years.

Electoral ward population data for 1991 (detailed small area statistics are only available for census years) were used to calculate average annual stroke mortality rates (deaths per 100000 population) by ward, sex, and age band for the period 1986-92. ${ }^{7}$ Ward based ethnicity data for the relevant age bands were also obtained from the 1991 census. The percentages of men and women in four groups (Afro-Caribbeans, Asians, Irish born, others) were then calculated by ward and age band.

The Carstairs index was used as a measure of socioeconomic deprivation and has previously been shown to predict stroke mortality at the small area level. ${ }^{3}$ Using Great Britain as the standard population, the index combined four indicators at the electoral ward level from the 1991 census - the percentage of people with no car, in overcrowded housing, with the household head in social class IV or V, and the percentage of men unemployed. 
Table 1 Average annual stroke mortality (1986-92) - deaths per 100000 population (95\% confidence intervals) and number of stroke deaths 1986-92 in Inner and Outer London and the surrounding South East Region

\begin{tabular}{|c|c|c|c|}
\hline Age (y) & Inner London & Outer London & Surrounding south east \\
\hline \multicolumn{4}{|l|}{ Men: } \\
\hline $45-54$ & $\begin{array}{l}33 \\
(29,37) \\
(\mathrm{n}=278)\end{array}$ & $\begin{array}{l}21 \\
(19,23) \\
(n=331)\end{array}$ & $\begin{array}{l}16 \\
(15,17) \\
(n=687)\end{array}$ \\
\hline $55-64$ & $\begin{array}{l}102 \\
(95,109) \\
(\mathrm{n}=796)\end{array}$ & $\begin{array}{l}75 \\
(70,80) \\
(n=1033)\end{array}$ & $\begin{array}{l}64 \\
(61,67) \\
(n=2341)\end{array}$ \\
\hline $65-74$ & $\begin{array}{l}315 \\
(300,330) \\
(n=1829)\end{array}$ & $\begin{array}{l}282 \\
(272,292) \\
(\mathrm{n}=2942)\end{array}$ & $\begin{array}{l}276 \\
(270,282) \\
(n=7959)\end{array}$ \\
\hline $75-84$ & $\begin{array}{l}961 \\
(926,996) \\
(n=2877)\end{array}$ & $\begin{array}{l}946 \\
(921,971) \\
(\mathrm{n}=5497)\end{array}$ & $\begin{array}{l}1015 \\
(1000,1030) \\
(n=15903)\end{array}$ \\
\hline 85 or more & $\begin{array}{l}2010 \\
(1891,2129) \\
(n=1076)\end{array}$ & $\begin{array}{l}2166 \\
(2079,2253) \\
(n=2320)\end{array}$ & $\begin{array}{l}2439 \\
(2384,2494) \\
(n=7492)\end{array}$ \\
\hline \multicolumn{4}{|l|}{ Women: } \\
\hline $45-54$ & $\begin{array}{l}23 \\
(20,26) \\
(n=201)\end{array}$ & $\begin{array}{l}16 \\
(14,18) \\
(n=260)\end{array}$ & $\begin{array}{l}14 \\
(13,15) \\
(n=606)\end{array}$ \\
\hline $55-64$ & $\begin{array}{l}66 \\
(60,72) \\
(n=513)\end{array}$ & $\begin{array}{l}53 \\
(49,57) \\
(n=764)\end{array}$ & $\begin{array}{l}50 \\
(48,52) \\
(n=1907)\end{array}$ \\
\hline $65-74$ & $\begin{array}{l}234 \\
(223,245) \\
(n=1651)\end{array}$ & $\begin{array}{l}222 \\
(214,230) \\
(n=2924)\end{array}$ & $\begin{array}{l}217 \\
(212,222) \\
(n=7722)\end{array}$ \\
\hline $75-84$ & $\begin{array}{l}848 \\
(823,873) \\
(n=4517)\end{array}$ & $\begin{array}{l}869 \\
(851,887) \\
(n=8782)\end{array}$ & $\begin{array}{l}956 \\
(944,968) \\
(n=25000)\end{array}$ \\
\hline 85 or more & $\begin{array}{l}2304 \\
(2234,2374) \\
(n=4045)\end{array}$ & $\begin{array}{l}2525 \\
(2472,2578) \\
(n=8474)\end{array}$ & $\begin{array}{l}2874 \\
(2840,2908) \\
(n=26120)\end{array}$ \\
\hline
\end{tabular}

STATISTICAL ANALYSIS

Log linear Poisson regression analysis was used to assess whether deprivation and ethnicity significantly influenced stroke mortality at the electoral ward level and to see if they explained the different levels of stroke mortality in Inner London, Outer London and the surrounding South East Region. ${ }^{8}$ Data were sparse (expectation of less than two deaths per ward in the younger age bands) and deaths were assumed to occur independently across wards. Area was entered as a categorical variable. The Carstairs index and the percentages of ethnic minorities and Irish born people were entered as continuous variables. Regression parameter estimates are presented as rate ratios $(95 \%$ confidence intervals (CI)). Significance tests and CI were adjusted for extra-Poisson variability.

Each sex and age band combination was analysed separately. The age adjusted effects of ethnicity were then assessed in further analyses entering age bands as categorical variables with age in relation to area and age in relation to Carstairs interaction terms. Statistical analysis was carried out using $S A S .^{9}$
Table 3 Association between Carstairs index and stroke mortality in relation to age - rate ratios* for stroke mortality for a ward on the 95th centile relative to a ward on the 5th centile (95\% confidence intervals)

\begin{tabular}{llllll}
\hline & \multicolumn{3}{l}{ Men } & \multicolumn{3}{l}{ Women } \\
\cline { 2 - 3 } \cline { 5 - 6 } Age $(y)$ & Rate ratio & $(95 \%$ CI $)$ & & Rate ratio & $(95 \% C I)$ \\
\hline $45-54$ & 2.21 & $(1.76,2.76)$ & 2.46 & $(1.92,3.14)$ \\
$55-64$ & 2.14 & $(1.88,2.44)$ & 2.11 & $(1.83,2.43)$ \\
$65-74$ & 1.44 & $(1.33,1.55)$ & 1.42 & $(1.31,1.53)$ \\
$75-84$ & 1.13 & $(1.06,1.21)$ & 1.01 & $(0.94,1.08)$ \\
85 or more & 0.98 & $(0.89,1.08)$ & 0.91 & $(0.85,0.98)$ \\
\hline
\end{tabular}

*Adjusted for area and ethnic and Irish born populations.

Results

STROKE MORTALITY IN INNER LONDON, OUTER LONDON, AND THE SURROUNDING SOUTH EAST REGION

A gradient in stroke mortality across areas was observed for men and women, which varied with age (table 1). For people aged 45-54 years, stroke mortality was highest in Inner London, lower in Outer London, and lowest in the surrounding south east. This gradient diminished with increasing age and was reversed in the oldest age bands, being lowest in Inner London and highest in the surrounding south east.

DISTRIBUTION OF CARSTAIRS DEPRIVATION SCORES AND ETHNIC MINORITY GROUPS Inner London wards tended to have high Carstairs scores indicating that they had high levels of deprivation (table 2). Negative Carstairs scores in the surrounding south east indicated relative affluence.

The percentages of Afro-Caribbeans, Asians, other ethnic groups, and people born in Ireland tended to be higher in London than the surrounding south east (table 2 ). The percentages of these groups also tended to be higher in the younger age bands (not shown).

INFLUENCE OF DEPRIVATION AND ETHNICITY ON VARIATION IN STROKE MORTALITY ACROSS ELECTORAL WARDS

For men and women aged 45-54 years, there was a significant positive association between stroke mortality and Carstairs index. However, for both sexes the effect of Carstairs index diminished with increasing age (table 3 ). This

Table 2 Carstairs scores and ethnic minority and Irish born populations aged 45 years or more in Inner and Outer London and the surrounding South East Region, 1991

\begin{tabular}{llll}
\hline & Inner London & Outer London & Surrounding south east \\
\hline No of electoral wards & 300 & 460 & 2176 \\
Median Carstairs score (1st, 3rd quartiles) & 5.5 & 0.1 & -1.9 \\
Men: & $(2.5,7.9)$ & $(-1.8,2.8)$ & $(-3,-0.3)$ \\
Population aged 45 years or more & 366803 & 675188 & 1827602 \\
Afro-Caribbeans (\%) & 9.3 & 3 & 0.4 \\
Asians (\%) & 5.2 & 5.8 & 0.9 \\
Others (\%) & 2.9 & 2.1 & 0.5 \\
Irish born (\%) & 8 & 4.8 & 2.2 \\
Women: & 440044 & 823036 & 2178247 \\
Population aged 45 years or more & 7.8 & 2.5 & 0.3 \\
Afro-Caribbeans (\%) & 3.2 & 4.2 & 0.6 \\
Asians (\%) & 2.6 & 1.7 & 0.4 \\
Others (\%) & 7.5 & 5 & 2.4 \\
Irish born (\%) & & & \\
\hline
\end{tabular}


Table 4 Association between ethnic minority and Irish born populations and stroke mortality - rate ratios* for $10 \%$ higher prevalence (95\% confidence intervals)

\begin{tabular}{|c|c|c|c|c|}
\hline & \multicolumn{2}{|l|}{ Men } & \multicolumn{2}{|l|}{ Women } \\
\hline & Rate ratio & $(95 \% C I)$ & Rate ratio & $(95 \% C I)$ \\
\hline $\begin{array}{l}\text { Afro-Caribbeans } \\
\text { Asians } \\
\text { Others } \\
\text { Irish born }\end{array}$ & $\begin{array}{l}1.08 \\
0.94 \\
1.02 \\
1.05\end{array}$ & $\begin{array}{l}(1.04,1.12) \\
(0.91,0.97) \\
(0.91,1.13) \\
(1.01,1.09)\end{array}$ & $\begin{array}{l}1.09 \\
0.95 \\
0.87 \\
1.01\end{array}$ & $\begin{array}{l}(1.03,1.15) \\
(0.90,1.00) \\
(0.765,0.996) \\
(0.97,1.05)\end{array}$ \\
\hline
\end{tabular}

* Adjusted for age, area and Carstairs index.

diminishing effect was also seen when data for Greater London and the surrounding south east were analysed separately.

There were significant positive associations between the percentages of Afro-Caribbean men $(p=0.0001)$ and women $(p=0.003)$ in a ward and age adjusted stroke mortality for men and women respectively (table 4 ). The percentage of Irish born men was also significantly and positively associated with male stroke mortality $(p=0.007)$. The percentage of Asian men and percentage of women from other ethnic groups were negatively associated with stroke mortality $(p=0.0005$ and $p=0.04$ respectively).

STROKE MORTALITY IN INNER LONDON, OUTER LONDON, AND THE SURROUNDING SOUTH EAST AFTER ADJUSTMENT FOR DEPRIVATION AND ETHNICITY

For men and women in the younger age bands, for whom the risk of mortality from stroke was higher in Inner and Outer London relative to the surrounding South East Region, adjustment for Carstairs index and the percentages of ethnic minorities and Irish born people diminished or abolished this increased risk. For men and women in the older age bands, for whom the risk of mortality from stroke was lower in Inner and Outer London relative to the surrounding south east, adjustment had little effect on this lower relative risk (table 5).
Adjustment for the percentage of Afro-Caribbeans only (in addition to Carstairs index) instead of all four ethnic groups produced similar results.

\section{Discussion}

SOCIOECONOMIC DEPRIVATION AND STROKE MORTALITY

There was a clear association between deprivation and raised mortality from stroke in younger people but the magnitude of this association diminished with age. This is consistent with the observation that the gradient of association between deprivation and mortality from all causes is considerably less steep for people aged 65 or more years compared with those aged $0-64$ years. $^{3}$

A deprivation index comprising four variables at the electoral ward level, three of which are in the Carstairs index, appears to be a good indicator of deprivation at the individual level for people aged under 65 years. ${ }^{10}$ Nevertheless, the diminishing effect of Carstairs index on stroke mortality with increasing age could still be an artefact as this index may be a relatively insensitive measure of deprivation for older people. This could also be an ecological fallacy - ie, old people with stroke in wards with low Carstairs scores are deprived at the individual level. However, data from studies on individuals also show this diminishing effect of socioeconomic deprivation with increasing age, both for stroke and for all-cause mortality. ${ }^{112}$ The diminishing effect on stroke was seen even in relatively young age bands. ${ }^{11}$ This suggests that the diminishing effect of deprivation on stroke mortality with increasing age may be real.

It is possible that deprived people who are susceptible to stroke die at relatively young ages but it is unlikely that this occurs commonly enough to account for the lack of association among older people. Another possibility is that older people belong to earlier generations

Table 5 Unadjusted and adjusted rate ratios (95\% confidence intervals) for stroke mortality (1986-92) in Inner and Outer London relative to the surrounding South East Region

\begin{tabular}{|c|c|c|c|c|c|c|}
\hline \multirow[b]{2}{*}{ Age (y) } & \multicolumn{3}{|c|}{ Unadjusted rate ratio $(95 \% C I)$} & \multicolumn{3}{|c|}{ Adjusted rate ratio $(95 \% C I)^{*}$} \\
\hline & Inner London & Outer London & $\begin{array}{l}\text { Surrounding } \\
\text { south east }\end{array}$ & Inner London & Outer London & $\begin{array}{l}\text { Surrounding } \\
\text { south east }\end{array}$ \\
\hline \multicolumn{7}{|l|}{ Men: } \\
\hline $45-54$ & $\begin{array}{l}2.09 \\
(1.81,2.40)\end{array}$ & $\begin{array}{l}1.31 \\
(1.15,1.50)\end{array}$ & 1 & $\begin{array}{l}1.01 \\
(0.81,1.26)\end{array}$ & $\begin{array}{l}1.07 \\
(0.90,1.26)\end{array}$ & 1 \\
\hline $55-64$ & $\begin{array}{l}1.59 \\
(1.46,1.73)\end{array}$ & $\begin{array}{l}1.16 \\
(1.07,1.26)\end{array}$ & 1 & $\begin{array}{l}0.85 \\
(0.75,0.98)\end{array}$ & $\begin{array}{l}1.02 \\
(0.93,1.12)\end{array}$ & 1 \\
\hline $65-74$ & $\begin{array}{l}1.14 \\
(1.07,1.21)\end{array}$ & $\begin{array}{l}1.02 \\
(0.97,1.07)\end{array}$ & 1 & $\begin{array}{l}0.84 \\
(0.77,0.92)\end{array}$ & $\begin{array}{l}0.95 \\
(0.90,1.01)\end{array}$ & 1 \\
\hline $75-84$ & $\begin{array}{l}0.95 \\
(0.90,0.99)\end{array}$ & $\begin{array}{l}0.93 \\
(0.90,0.97)\end{array}$ & 1 & $\begin{array}{l}0.86 \\
(0.80,0.92)\end{array}$ & $\begin{array}{l}0.92 \\
(0.88,0.96)\end{array}$ & 1 \\
\hline 85 or more & $\begin{array}{l}0.82 \\
(0.76,0.89)\end{array}$ & $\begin{array}{l}0.89 \\
(0.84,0.94)\end{array}$ & 1 & $\begin{array}{l}0.83 \\
(0.75,0.92)\end{array}$ & $\begin{array}{l}0.90 \\
(0.85,0.96)\end{array}$ & 1 \\
\hline $\begin{array}{l}\text { Women: } \\
45-54\end{array}$ & $\begin{array}{l}1.64 \\
(1.40,1.93)\end{array}$ & $\begin{array}{l}1.13 \\
(0.98,1.31)\end{array}$ & 1 & $\begin{array}{l}0.89 \\
(0.68,1.16)\end{array}$ & $\begin{array}{l}1.02 \\
(0.85,1.22)\end{array}$ & 1 \\
\hline $55-64$ & $\begin{array}{l}1.30 \\
(1.18,1.44)\end{array}$ & $\begin{array}{l}1.05 \\
(0.96,1.15)\end{array}$ & 1 & $\begin{array}{l}0.77 \\
(0.66,0.90)\end{array}$ & $\begin{array}{l}0.97 \\
(0.87,1.07)\end{array}$ & 1 \\
\hline $65-74$ & $\begin{array}{l}1.08 \\
(1.02,1.15)\end{array}$ & $\begin{array}{l}1.02 \\
(0.97,1.07)\end{array}$ & 1 & $\begin{array}{l}0.84 \\
(0.77,0.91)\end{array}$ & $\begin{array}{l}0.97 \\
(0.92,1.02)\end{array}$ & 1 \\
\hline $75-84$ & $\begin{array}{l}0.89 \\
(0.84,0.93)\end{array}$ & $\begin{array}{l}0.91 \\
(0.87,0.95)\end{array}$ & 1 & $\begin{array}{l}0.86 \\
(0.80,0.92)\end{array}$ & $\begin{array}{l}0.91 \\
(0.87,0.95)\end{array}$ & 1 \\
\hline 85 or more & $\begin{array}{l}0.80 \\
(0.75,0.85)\end{array}$ & $\begin{array}{l}0.88 \\
(0.84,0.92)\end{array}$ & 1 & $\begin{array}{l}0.87 \\
(0.80,0.93)\end{array}$ & $\begin{array}{l}0.90 \\
(0.86,0.94)\end{array}$ & 1 \\
\hline
\end{tabular}

* Adjusted for Carstairs index and ethnic minority and Irish born populations. 
Table 6 Standardised mortality ratios for stroke for men

\begin{tabular}{lllllll}
\hline Year & $1921-23$ & $1930-32$ & $1949-53$ & $1959-63$ & $1970-72$ & $1979-83$ \\
\hline Age (y) & $20-64$ & $20-64$ & $20-64$ & $15-64$ & $15-64$ & $20-64$ \\
Social class: & & & & & & \\
I & 88 & 112 & 124 & 86 & 80 & 62 \\
II & 103 & 106 & 104 & 89 & 86 & 72 \\
III (N/M) & 100 & 100 & 101 & 101 & $98 / 106$ & $89 / 109$ \\
IV & 94 & 96 & 88 & 98 & 111 & 117 \\
V & 108 & 97 & 101 & 135 & 136 & 179 \\
\hline
\end{tabular}

England and Wales $=100$

Data from decennial supplements on occupational mortality. ${ }^{411314}$

among whom deprivation was not a risk factor for stroke. If this were the case, no association between deprivation and stroke would be expected in the early years of this century, with this association gradually emerging with time. Standardised mortality ratios for stroke by social class among men of working age showed a negative gradient in 1930-32 and 1949-53 but a rather abrupt change to a clear positive gradient from 1959-63 onwards (table 6). ${ }^{4111314}$ Persons aged $75-84$ in $1986-92$ would have been aged 55-64 around 1971, when there was already evidence of a social class gradient in stroke mortality among men of that age. The standardised mortality ratios in relation to social class therefore do not show the expected cohort pattern but have to be interpreted with caution as social class definitions have changed considerably over the years.

Higher levels of deprivation, in conjunction with ethnicity, largely account for higher stroke mortality rates for middle aged people in Greater London compared with the surrounding South East Region. It is possible that increasing relative deprivation in Greater London could also account for the slower rate of decline in stroke mortality. ${ }^{1}$ Although there is no direct evidence for this, relative deprivation and inequalities in mortality have increased in other parts of the United Kingdom between 1981 and $1991 . .^{15}$ In addition, a stronger association between unemployment and stroke mortality in 1981 compared with 1971 in Greater London has been reported and the authors suggest that major increases in unemployment over the decade might explain their results. ${ }^{17}$

\section{ETHNICITY AND STROKE MORTALITY}

The relative risks of stroke mortality for AfroCaribbean men and women in this study are consistent with those from the study of migrant mortality in England and Wales where the unit of analysis was the individual. ${ }^{5}$ However, the possibility of ecological bias could account for the lack of association or negative associations between the other ethnic groups and stroke mortality (ie, the association found at the area level is different from that which exists at the individual level). Misclassification of ethnicity and random error introduced to protect confidentiality surrounding small numbers could also have reduced the likelihood of finding an association. ${ }^{1819}$

Afro-Caribbeans have a high prevalence of hypertension which may contribute to their increased risk of stroke. ${ }^{20}$ However, deprivation may also explain this increased risk as higher mortality from circulatory diseases among Afro-Caribbeans is abolished when socioeconomic factors are taken into account. ${ }^{21}$

OTHER RISK FACTORS FOR STROKE

Data on other risk factors for stroke in Greater London and the surrounding south east are limited and based on relatively small samples. ${ }^{2223}$ In the health and lifestyle survey, based on a sample of 2600 people, the prevalence of hypertension was marginally lower in Greater London than the surrounding South East Region $(22 \%$ of men and $18 \%$ of women in Greater London v 25\% and $21 \%$ respectively in the surrounding south east). ${ }^{22}$ The percentage of non-drinkers or very occasional drinkers was marginally higher in Greater London ( $16 \%$ of men and $37 \%$ of women in Greater London $\mathrm{v} 14 \%$ and $31 \%$ respectively in the surrounding south east). Fruit and salad consumption in summer, an indication of vitamin C intake, tended to be marginally lower in Greater London. There were no consistent differences in the body mass index.

In the general household survey, the prevalence of smoking has been slightly higher in Greater London (29\% in Greater London v $27 \%$ in the surrounding south east in 1992 based on 5500 people). ${ }^{23}$ The percentage of non-drinkers has also been higher in Greater London (11\% of men and $18 \%$ of women in Greater London v 5\% and 9\% respectively in the surrounding south east in 1992), consistent with the results from the health and lifestyle survey.

The above data are largely for people under 75 years of age among whom stroke mortality is now higher in Greater London than in the surrounding South East Region. The higher prevalence of smoking, lower consumption of fresh fruit and salads, and possibly the higher prevalence of non-drinkers if a $U$ shaped relationship between alcohol and stroke is accepted, ${ }^{24}$ are consistent with this higher stroke mortality in Greater London, but the marginally lower prevalence of hypertension is not. Smoking, in particular, is interesting as its association with stroke diminishes substantially with increasing age (in a meta-analysis the relative risks were 2.94 for people under 55 , 1.75 for people aged 55-74, and 1.11 in people over 74)..$^{25}$ As higher levels of smoking are associated with greater socioeconomic deprivation, this could partly explain the diminishing socioeconomic effect on stroke with increasing age observed in our study. However, these data on other risk factors have to be interpreted cautiously as they are based on relatively small numbers.

\section{CONCLUSIONS}

Stroke mortality rates for middle aged Londoners are higher, but for older Londoners are lower, than rates for people in the rest of the South East Region of England. We found that socioeconomic deprivation and ethnicity largely explained the raised mortality rates for 
middle aged Londoners. This suggests that factors associated with socioeconomic deprivation and ethnicity, including smoking, diet, and access to effective health care, need to be addressed in order to reduce mortality from stroke in London.

1 Maheswaran R, Strachan D, Elliott P, Shipley MJ. Trends in stroke mortality in Greater London and south east England - evidence for a cohort effect? I Epidemiol Community Health 1997;51:121-26.

2 Department of Health. Common data set - health of the nation baseline indicators. London: Department of Health, 1992. baseline indicators. London: Department of Health, 1992. Health Bull 1990;48:162-75.

4 Office of Population Censuses and Surveys. Occupational mortality - decennial supplement. 1979-80, 1982-83. Lon-

5 Balarajan R. Ethnic differences in mortality from ischaemic heart disease and cerebrovascular disease in England and Wales. BMF 1991;302:560-4.

6 Caplan LR. Strokes in African-Americans. Circulation 1991; 83:1469-71.

7 SASPAC user manual. Manchester: Manchester Computing Centre, 1992.

8 Breslow NE, Day NE. Statistical methods in cancer research Vol II - the design and analysis of cohort studies. Lyon: IARC, 1977.

9 SAS Institute Inc. SAS Technical report P-243, SAS/STAT Software: The GENMOD procedure. Release 6.09. Cary, Software: The GENMOD proced

10 Sloggett A, Joshi H. Higher mortality in deprived areas: community or personal disadvantage? $B M F$ 1994;309: $1470-4$

11 Office of Population Censuses and Surveys. Occupational mortality decennial supplement 1970-72. London: HMSO, 1978:54-60.

12 Kaplan GA Seeman TE, Cohen RD, Knudsen LP, Guralnik J. Mortality among the elderly in the Alameda county study: behavioral and demographic risk factors. $A m \mathcal{F}$ study: behavioral and demograp

13 The Registrar General's decennial supplement - England and Wales 1951. Occupational mortality Part II. London: HMSO, 1958:45.

14 Annual report of the Registrar General - decennial supplemen 1961. Occupational mortality. London: HMSO, 1971:38.

15 Phillimore P, Beattie A, Townsend P. Widening inequality of health in northern England, 1981-91. BMf 1994;308 $1125-8$

16 McLoone P, Boddy FA. Deprivation and mortality in Scotland, 1981 and 1991. BMF 1994;309:1465-70.

17 Franks P, Adamson C, Bulpitt PF, Bulpitt CJ. Stroke death and unemployment in London. $f$ Epidemiol Community Health 1991;45:16-8.

18 Dale A, Marsh C. The 1991 census user's guide. London: HMSO, 1993.

19 Office of Population Censuses and Surveys. First quality check results from the 1991 census validation survey. London HMSO. Census newsletter 1994; No 29.

20 Chaturvedi N, McKeigue PM, Marmot MG. Resting and ambulatory blood pressure differences in Afro-Caribbeans and Europeans. Hypertension 1993;22:90-6.

21 Rogers RG. Living and dying in the USA: Socioeconomic determinants of death among blacks and whites. Demography 1992;29:287-303.

22 Cox BD, Blaxter M, Buckle ALJ, et al. The health and lifestyle survey London: Health Promotion Research Trust, 1987. 23 Office of Population Censuses and Surveys. General household survey 1992. London: HMSO, 1994. No 23.

24 Gill JS, Zezulka AV, Shipley MJ, Gill SK, Beevers DG Stroke and alcohol consumption. N Engl F Med 1986;315: Stroke and

25 Shinton R, Beevers G. Meta-analysis of relation between cigarette smoking and stroke. BMF 1989;298:789-94. 